\title{
Polysialic Acid Is Required for Optimal Growth of Axons on a Neuronal Substrate
}

\author{
Hong Zhang, ' Robert H. Miller, ${ }^{1}$ and Urs Rutishauser ${ }^{1,2}$ \\ Departments of 'Neurosciences and ${ }^{2}$ Genetics, School of Medicine, Case Western Reserve University, Cleveland, \\ Ohio 44106-4901
}

\begin{abstract}
Formation of axonal pathways involves a variety of molecules that influence cell-cell interactions. The polysialic acid (PSA) moiety of the neural cell adhesion molecule (NCAM) is present on neuronal surfaces during process outgrowth. Our studies reveal that the removal of PSA causes a decrease in the rate of elongation of retinal cell processes on a substrate of neuronal membranes derived from chick tectum. This effect was partially reversed by antibodies against the $\mathrm{L} 1$ adhesion molecule, but not by antibodies against NCAM, $\mathbf{N}$-cadherin, or $\beta_{1}$-integrins. This predominant effect of PSA on L1 was also observed in short-term, cell-cell adhesion assays, suggesting that PSA promotes optimal outgrowth on neuronal substrates by limiting the consequences of $L 1$-mediated adhesion.
\end{abstract}

Axons follow intricate yet reproducible pathways during development of the nervous system, and it remains a major goal to describe the mechanisms that contribute to axonal tract formation. One of the essential factors in the growth of axons is the adhesiveness of their environment (Letourneau, 1975a,b). That is, there is no axon elongation in the absence of adhesion between the growth cone and its substrate. Accordingly, a number of adhesion molecules present on cells have been shown to promote axon elongation (Lagenaur and Lemmon, 1987; Lemmon et al., 1989; Ruegg et al., 1989; Bixby and Zhang, 1990; Doherty et al., 1990a,b; Furley et al., 1990; Stoeckli et al., 1991), and antibodies that specifically inhibit the function of adhesion molecules can block outgrowth on cellular substratcs (Tomasclli et al., 1986, 1988; Chang et al., 1987; Landmesser et al., 1988; Smith et al., 1990).

The relationship between the degree of cell-cell adhesion and the rate of growth cone migration is complex, however, in that there is an inconsistent and sometimes even inverse correlation between these two parameters (Lemmon et al., 1992). Several explanations for this complexity are possible, such as the triggering of intracellular events that promote or inhibit growth cone migration (Kapfhammer and Raper, 1987; Bixby, 1989; Schuch et al., 1989; Raper and Grunewald, 1990). Moreover,

\footnotetext{
Received Jan. 15, 1992; accepted Mar. 16, 1992.

We thank Drs. George Smith, Vance Lemmon, and Fricdrich Bonhocffer for their advice in the design of these experiments; Dr. A. Acheson for performing the aggregation assay; and Denice Major and Vilma Szigeti for excellent technical assistance. This work was supported in part by NIH Grants HD18369 (U.R.), EY06107 (U.R.), and NS25597 (R.H.M.).

Correspondence should be addressed to Urs Rutishauser, Department of Genetics, School of Medicine, Case Western Reserve University, 2040 Adelbert Road, Cleveland, $\mathrm{OH}$ 44106-4901.

Copyright (C) 1992 Society for Neuroscience $0270-6474 / 92 / 123107-08 \$ 05.00 / 0$
}

migration requires both the making and breaking of adhesions, and therefore could be hindered either by insufficient or by excessive substrate interaction (Letourneau and Wessells, 1974).

It is important, therefore, to consider not only the specificity but also the degree and nature of adhesive interaction of axons with their environment. The regulation of the extent of adhesivity can in principle be achieved through transcriptional control of the type and amount of adhesion molecules expressed on the cell surface membrane. However, in several tissues including those of the nervous system, an additional mechanism exists to regulate cell-cell interactions, namely, the expression of cell surface polysialic acid (PS $\Lambda$ ). $\Lambda$ nchored to the cell surface via its covalent attachment to the neural cell adhesion molecule (NCAM) (Finne et al., 1983), this unusual carbohydrate polymer has been proposed to decrease membrane-membrane contact, and thereby to attenuate cell interactions (Rutishauser et al., 1988; Rutishauser, 1989). PSA is abundant on growing axons during both development and regeneration (Schlosshauer et al., 1984; Breen and Regan, 1988; Miragall et al., 1990; Boisseau et al., 1991; Theodosis et al., 1991), and is thus in a position to influence their behavior. Although PSA is attached to NCAM, its presence has been shown to affect interactions involving other molecules that promote neurite outgrowth, such as laminin and the L1 adhesion molecule (Rutishauser et al., 1988; Acheson et al., 1991).

In the present study, we test directly the role of PSA in outgrowth of individual neuronal processes from embryonic chick retinal cells on a neuronal membrane substrate. This system is intended to model growth of axons on other axons, such as occurs during fascicle formation in vivo. It is shown that specific enzymatic removal of PSA causes a decrease in process outgrowth from retinal cells on the neuronal membrane substrate. The molecular basis of the PSA effect has been examined using antibodies against adhesion molecules known to be involved in axonal elongation. The results obtained in the outgrowth assay, and their striking similarity to data obtained in a cell-cell adhesion assay, suggest that the promotion of axon growth by PSA reflects a selective limiting of $\mathrm{L} 1$-mediated adhesive functions and their consequences for neurite-neurite interaction.

\section{Materials and Methods}

Tectal membrane vesicle substrates. Tectal membrane vesicle substrates were prepared using a modification of the method of Walter et al. (1987) Embryonic day (E12) White Leghorn chick anterior tecta were dissected and meninges removed. The tissue was rinsed and homogenized in homogenization buffer $\left(10 \mathrm{~mm}\right.$ Tris- $\mathrm{HCl}, 1.5 \mathrm{~mm} \mathrm{CaCl}_{2}, 200 \mathrm{KIU}$ aprotinin, $1 \mathrm{~mm}$ spermidine, $50 \mu \mathrm{M}$ leupeptin, and $2 \mu \mathrm{M}$ pepstatin $\mathrm{A}, \mathrm{pH}$ 7.4). Membranes were isolated by centrifugation at $50,000 \times \mathrm{g}$ for 10 min through $2 \mathrm{ml}$ of $5 \%$ sucrose in buffer onto $5 \mathrm{ml}$ of $50 \%$ sucrose. 
The membrane fraction was collected from the sucrose interface and washed three times in phosphate-buffered saline (PBS) by centrifugation for $5 \mathrm{~min}$ at $13,000 \times \mathrm{g}$. The membranes were diluted in PBS to yield a suspension that had an optical density of 0.3 at $220 \mathrm{~nm}$ when diluted $1: 10$ in $2 \%$ SDS.

To prepare vesicle substrates, a Nucleopore filter $(25 \mathrm{~mm}$ polycarbonate, pore size $0.1 \mu \mathrm{m}$ ) was placed on a nylon grid sitting over a porous support connected to a vacuum aspirator. Three hundred microliters of the membrane suspension were added onto the filter, and suction ( $30 \mathrm{mbar}$ ) was applied for $3 \mathrm{~min}$. The membrane-covered filter was then rinsed in PBS and kept at $4^{\circ} \mathrm{C}$ until used.

Rat cortical astrocyte monolayers. Newborn rat cortical astrocytes were purified as described previously (Noble et al., 1984; Smith et al., 1990). The cells formed a confluent monolayer within $24 \mathrm{hr}$, of which at least $90 \%$ were glial fibrillary acidic protein positive and exhibited the morphology of flat fibroblastic type 1-like astrocytes; less than $1 \%$ of the cells were fibroblasts or $\mathrm{O} 2 \mathrm{~A}$ progenitor cells, and about $0.1 \%$ of the cells expressed the oligodendrocyte marker galactocerebroside. The remaining cells probably included immature astrocytes, endothelial cells, or microglia (Smith et al., 1990).

Immunohistochemistry of tectal membrane vesicles and tissue sections. To stain the tectal membrane vesicles with antibodies, the vesicle suspension was pelleted by centrifugation $(13,000 \times g, 5 \mathrm{~min})$ and resuspended in the appropriate dilution of primary antibody (see below) in 0.1 m phosphate buffer (PB) containing $25 \%$ normal goat serum (NGS). After $30 \mathrm{~min}$ incubation at room temperature, vesicles were washed three times in PB by centrifugation as above and resuspended in the secondary antibody solution (1:100 dilution of rhodamine-conjugated goat anti-mouse IgM or goat anti-rabbit Ig in PB containing $25 \%$ NGS). After a $30 \mathrm{~min}$ incubation, the vesicles were washed three times in PB and fixed with $4 \%$ paraformaldehyde for $10 \mathrm{~min}$. A drop of stained vesicle suspension was placed on a glass slide in 5\% propyl gallate in glycerol and viewed using a Nikon immunofluorescence microscope.

To prepare frozen sections of E12 chick tectum, isolated tecta were fixed in $4 \%$ paraformaldehyde in $\mathrm{PB}$ with $7 \%$ sucrose for $3 \mathrm{hr}$ at room temperature. Following incubation in $30 \%$ sucrose at $4^{\circ} \mathrm{C}$ overnight, the tissue was frozen and $7-\mu \mathrm{m}$-thick sections were cut using a Microm cryostat. The sections were rehydrated in PB for $15 \mathrm{~min}$ and incubated in the primary antibody solution in a humidified chamber overnight at room temperature. The sections were then washed three times in PB and incubated in the secondary antibody solution for $1 \mathrm{hr}$. After the final wash, the sections were mounted in 5\% propyl gallate in glycerol and examined as above.

Chick retinal neurons and neurite outgrowth cultures. E6 chick retinas were dissected and the pigmented epithelium removed. The tissue was incubated in $0.5 \mathrm{ml}$ of $\mathrm{Ca}^{2+}$, $\mathrm{Mg}^{2+}$-free-minimum essential medium containing $0.01 \%$ trypsin at $37^{\circ} \mathrm{C}$ for $15 \mathrm{~min}$, after which $0.5 \mathrm{ml}$ of horse serum and $25 \mu \mathrm{g}$ of DNase were added. The tissue was dispersed into single cells by trituration through a Pasteur pipette, and the cells pelleted at $1000 \times g$ for $5 \mathrm{~min}$. For cultures on the astrocyte monolayer substrate, the cell pellet was resuspended in Dulbecco's modified Eagle's medium $(\mathrm{DMEM}) / \mathrm{F} 12+2 \%$ FBS. For cultures on the membrane vesicle substrate, the cell pellet was resuspended in serum-free medium $(5 \mu \mathrm{g} / \mathrm{ml}$ insulin, $5 \mu \mathrm{g} / \mathrm{ml}$ transferrin, $5 \mu \mathrm{g} / \mathrm{ml}$ sodium sclenitc in DMEM/F12) (Bottenstein and Sato, 1979). Cells $\left(3 \times 10^{4}\right.$ in $\left.1 \mathrm{ml}\right)$ were added either to 24-well culture plates containing the astrocyte substrate or to $35 \mathrm{~mm}$ dishes containing the vesicle/filter substrate. The retinal cells were allowed to attach to the substrate for $2 \mathrm{hr}$ before addition of either endoneuraminidase- $\mathrm{N}$ (endo- $\mathrm{N}$ ) or antibody Fab fragments to the medium (see below). After $24 \mathrm{hr}$ of culture on neuronal membrane substrates or $16 \mathrm{hr}$ on astrocytes, long neurites had emerged from a subpopulation of the cells and were analyzed as described below.

Observation and quantitation of neurite outgrowth. Cultures on the membrane vesicle substrate were fixed after $24 \mathrm{hr}$ with $4 \%$ paraformaldehyde and $0.5 \%$ glutaraldehyde in $\mathrm{PB}$ and permeabilized with $0.1 \%$ Triton X-100 for $6 \mathrm{~min}$ at room temperature. The retinal cells were stained using a mouse monoclonal antibody against $\beta$-tubulin (Sigma) (Gozes and Barnstable, 1982) followed by fluoresccin-conjugated goat anti-mouse Ig.

To measure the length of neurites, images of neurons with a distinct process were recorded digitally using a Panasonic optic disk recorder. The length of the longest neurite emerging from a neuron was measured from the soma to the tip of the neurite using a Bioquant image analysis system. Values reported represent data collected in two to four independent experiments with a total number of 200-600 neurites measured.
Statistic comparison of average neurite lengths under different experimental conditions was performed using the $t$ test.

Antibody and endoneuraminidase reagents. The procedures for preparation of polyclonal rabbit $\mathrm{lg}$ and Fab against chick NCAM and L1 glycoprotein used in this study have been described previously (Frelinger and Rutishauser, 1986; Landmesser et al., 1988). The same procedure has been followed for polyclonal anti-N-cadherin with the antigen being prepared by affinity chromatography using the NCD2 antibody (Hatta and Takeichi, 1986). Chick I I was isolated using the G4 monoclonal antibody (Rathjen et al., 1987). The specificity of each of these polyclonal antibodies was defined by the following criteria: each antibody only identified the SDS-PAGE band(s) characteristic of the purified immunogen, anti-NCAM and anti-N-cadherin each specifically inhibited retina cell aggregation in the absence and presence of $10 \mathrm{~mm} \mathrm{Ca}{ }^{2+}$, respectively, and fasciculation of dorsal root ganglion neurites was strongly inhibited by anti-L1 but only slightly by anti-NCAM.

For immunohistology, rabbit polyclonal IgGs against chick NCAM and $\mathrm{Ll}$ were used at final concentrations of $20 \mu \mathrm{g} / \mathrm{ml}$ and $10 \mu \mathrm{g} / \mathrm{ml}$, respectively, for staining of cultures, and $2 \mu \mathrm{g} / \mathrm{ml}$ and $1 \mu \mathrm{g} / \mathrm{ml}$, respectively, for staining of sections. Mouse monoclonal antibody ascites against PSA (5A5) (Dodd et al., 1988) was used at 1:100 dilution for staining of cultures, and 1:500 for staining of sections.

For perturbation experiments, Fab fragments were dialyzed against 500 vol of DMEM/F12 overnight at $4^{\circ} \mathrm{C}$. Anti-NCAM, anti-Ll, and anti-N-cadherin were used at a final concentration of $0.5 \mathrm{mg} / \mathrm{ml}$. JG22 monoclonal antibody (Greve and Gottlicb, 1982) as ascites fluid was dialyzed and used at a 1:50 dilution. At this dilution, JG-22, which binds an epitope on $\beta_{1}$-integrin (Neugebauer and Reichardt, 1991), completely blocked the neurite outgrowth of retinal neurons on a laminincoated substrate (data not shown). Control experiments were carried out with $0.5 \mathrm{mg} / \mathrm{ml} \mathrm{Fab}$ prepared from nonimmune rabbit IgG.

Endo- $\mathrm{N}$ was purified to electrophoretic homogeneity by previously published procedures (Hallenbeck et al., 1987). This enzyme is specific for $\alpha$-2,8-linked sialic acid polymers with a minimum chain length of 5 (Vimr et al., 1984), and therefore does not degrade any other known sialic acid-containing structures. Endotoxin contamination was below detectable levels $(0.04 \mathrm{ng} / \mathrm{ml})$ as determined using the E-Toxate assay (Sigma).

To remove PSA from both neurites and the tectal membrane substrate, endo- $\mathrm{N}$ was addcd to the culture medium $2 \mathrm{hr}$ after retinal neurons were plated onto the substrate. To remove PSA only from the tectal membrane substrate, the substrate was incubated with endo- $\mathrm{N}$ at $4^{\circ} \mathrm{C}$ for $30 \mathrm{~min}$, washed with PBS four times, and kept at $4^{\circ} \mathrm{C}$ until used.

Aggregation of F11 cells. F1 1 cells are a hybrid of E1 7 mouse primary sensory ganglion neurons and rat neuroblastoma cells (Platika et al., 1985). F11 cells at 50\% confluence were detached from dishes by gentle mechanical pipetting and then pelleted at $100 \times g$ through a cushion of $3.5 \% \mathrm{BSA}$ in HEPES-buffered saline (HBS) $+10 \mathrm{mM} \mathrm{Ca}^{2+}+2 \%$ DNase. The pellet was resuspended in $\mathrm{L} 15+10 \%$ NuSerum, and cells were incubated with or without endo-N (see above) for $2 \mathrm{hr}$ at $37^{\circ} \mathrm{C}$. Following this incubation period, cells were repelleted as above and resuspended in 15-20 times the pellet volume in HBS/DNase/BSA containing either $1 \mathrm{~mm} \mathrm{Ca}{ }^{2+}$ or $2 \mathrm{~mm}$ EDTA. Cells were then preincubatcd with Fab fragments $(0.5 \mathrm{mg} / \mathrm{ml}$ final concentration) for $20 \mathrm{~min}$ at $4^{\circ} \mathrm{C}$. Cells plus Fab fragments were then diluted 1:7 in their respective media and allowed to aggregate with rotation at $70 \mathrm{rpm}$ at $37^{\circ} \mathrm{C}$. Aliquots were taken at 0 and $30 \mathrm{~min}$, fixed in $1 \%$ glutaraldehyde, and then evaluated for number of free particles of size $10-100 \mu \mathrm{m}$ using a Coulter counter. Data are expressed as percentage decrease in free particle number after $30 \mathrm{~min}$.

\section{Results}

Development of a simplified assay for study of axon growth on axons. Axons in vivo often grow along other axons to form fascicles. Fasciculation, however, is a very complex phenomenon involving a competition between axon-axon and axonenvironment interactions. In order to focus on the axon-axon component, an in vitro assay was designed in which individual axons were allowed to extend over a substrate composed of membranes largely derived from neuronal processes. The choice of embryonic retinal cells for these experiments was predicated on two major factors. First, the long processes readily obtained 

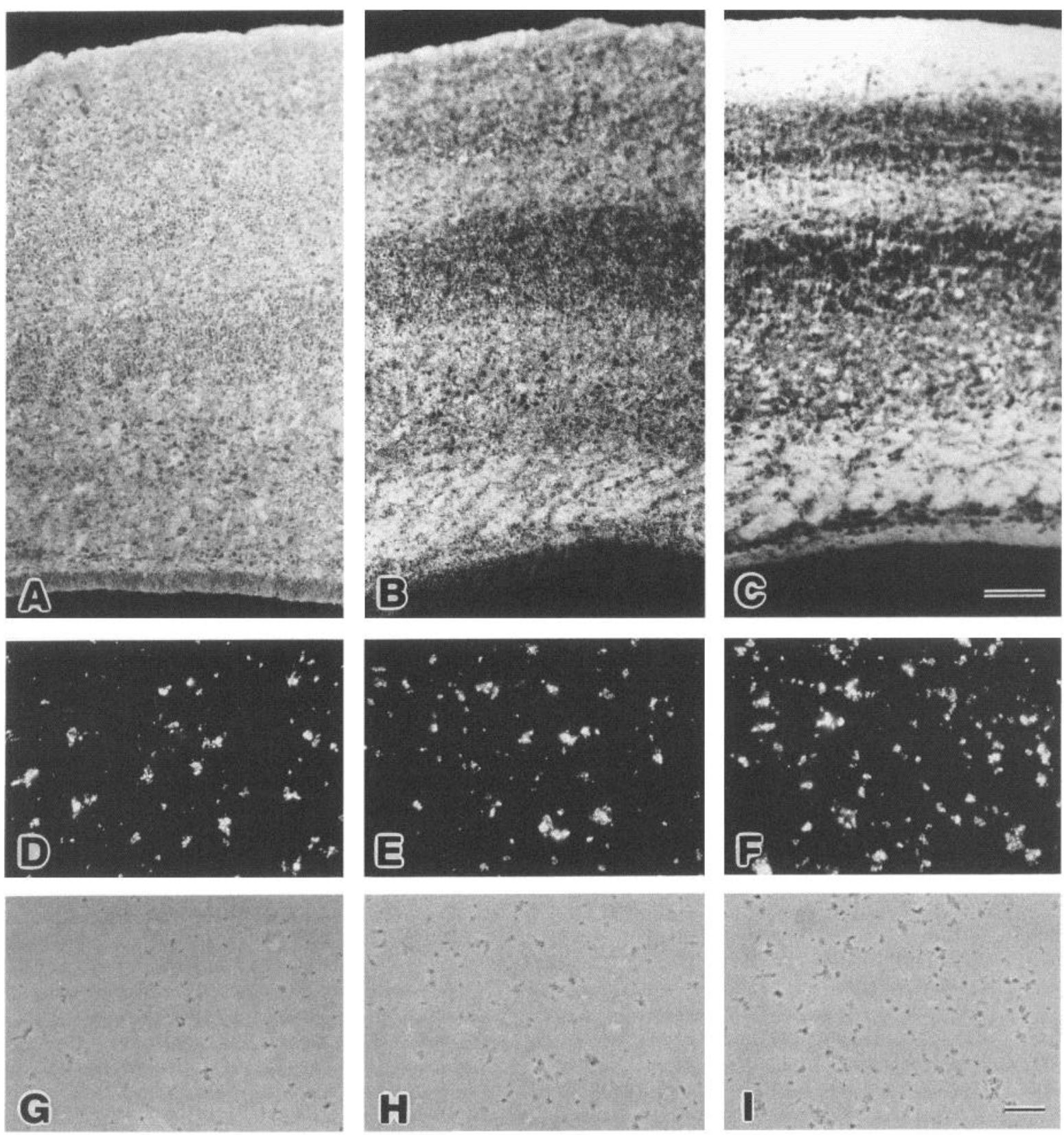

Figure 1. Purified tectal membrane vesicles display adhesion molecules characteristic of neuronal processes. NCAM, PSA, and L1 distribution in E12 chick tectum was determined by immunofluorescence microscopy of frozen sections. While NCAM $(A)$ was uniformly distributed in the tectum, PSA $(B)$ and $\mathrm{L} 1(C)$ were more concentrated in those tissue layers comprising mainly neuronal processes. For comparison, membrane vesicles purified from same-stage tectum were also stained with antibodies to NCAM, PSA, and L1. The majority of the membrane vesicles were labeled by all three antibodies: NCAM $(D)$, PSA $(E)$, and L1 $(F), G-I$ represent the corresponding phase micrographs of the vesicles. No staining of either the tissue or the membrane vesicles was observed when preimmune antibodies were used (data not shown). Scale bars: $C$ (for $A-C$ ), 20 $\mu \mathrm{m} ; I$ (for $D-I), 3 \mu \mathrm{m}$.

in short-term culture are $\beta$-tubulin, L1, and PSA positive (see below), and thus are likely to represent axons. Second, these axons readily form large fascicles both in culture and in the optic nerve. The most effective source of membranes for the substrate was density gradient-purified vesicles from E12 embryonic chick tectum. As shown in Figure 1, essentially all regions of E12 chick tectal tissue contain NCAM, whereas PSA is partially and $\mathrm{L} 1$ is highly concentrated in the process-rich regions of the optic fiber and deeper layers of neuropil. The large majority of the membrane vesicles prepared from this tissue were found to contain both L1 and PSA as well as NCAM antigenic determinants (Fig. 1). Thus, these membranes appear to be derived predominantly from fiber layers of the chick tectum.

The appearance of neuronal processes that have extended over the membrane substrate is shown in Figure 2. Both the processes and the substrate stained strongly for NCAM, PSA, and L1 (data not shown). While neurites could be detected before or after staining for these molecules, they were most easily analyzed for length after immunostaining for $\beta$-tubulin (Fig. $2 A$ ). When the PSA-specific endoneuraminidase (endo- $\mathrm{N}$ ) was added to the 

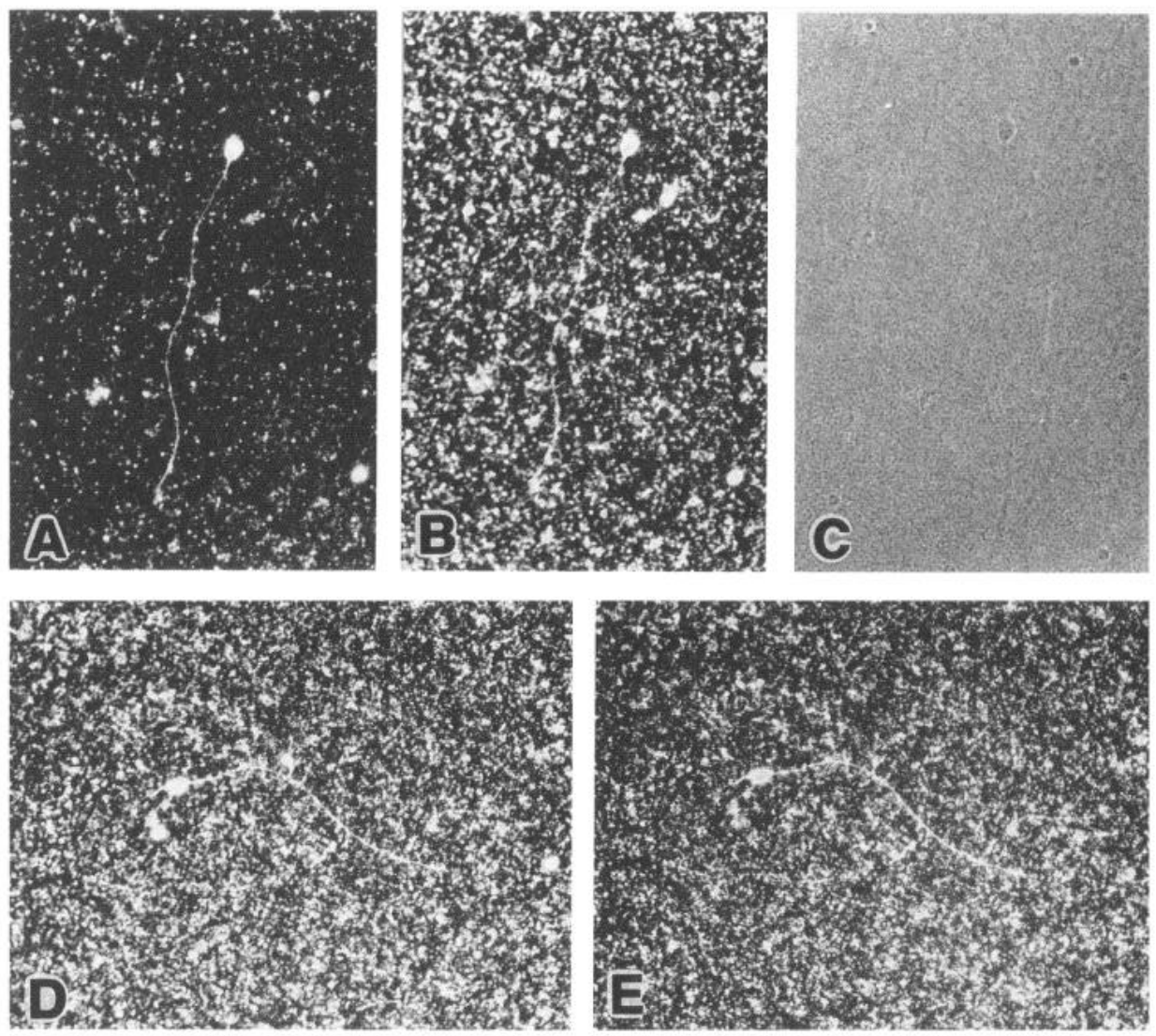

Figure 2. Adhesion molecule expression and neurite outgrowth of E6 chick retinal neurons on tectal membrane vesicles. Neurons were cultured on the substrate for $24 \mathrm{hr}$ and stained for $\beta$-tubulin $(A)$ and NCAM $(B) ; C$ is the corresponding phase micrograph. The ability of endo-N to remove PSA while not affecting the NCAM polypeptide was confirmed by double immunostaining of the culture with antibodies to NCAM $(D$, control; $F$, +endo-N), and PSA $(E$, control; $G$, + endo-N). Scale bar, $15 \mu \mathrm{m}$.
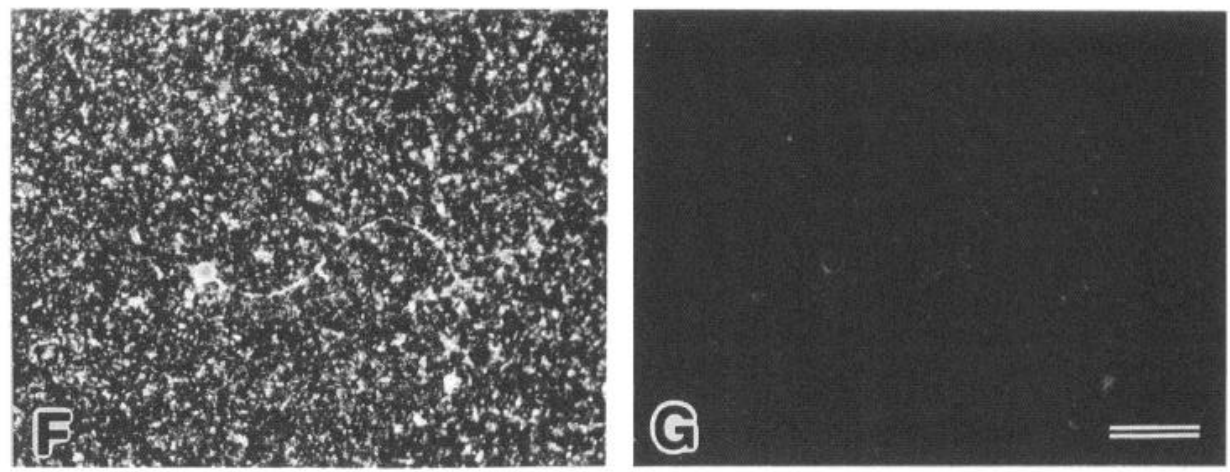

cultures, staining for PSA was completely abolished from both the neurites and vesicles, without a decrease in staining for NCAM (Fig. $2 D-G$ ).

Effect of PSA removal on growth of retinal neurites. When plated on the tectal membrane substrate and cultured for $24 \mathrm{hr}$, a subpopulation of the retinal cells displayed long neurites. There was usually only one process associated with a cell (Fig. 2), and these had a broad distribution of lengths (Fig. 3A). As reported previously (Smith et al., 1990), growth of these processes continues through out period of culture at a fairly uniform rate.

Exposure of both the neurite and substrate to endo-N during the culture period resulted in about a one-quarter decrease in the average length or rate of neurite outgrowth (Table 1). However, this significant $(p<0.001)$ but modest effect was found to include a more substantial decrease in the number of fibers capable of rapid outgrowth, with a corresponding increase in the proportion of shorter fibers (Fig. $3 B$ ). A decrease in average rate of neurite elongation was also observed when PSA was removed only from the neuronal substrate, that is, when the substrate was preincubated with endo- $\mathrm{N}$ and the enzyme was completely removed before addition of neurons (Table 1). Under these conditions, the retinal cells retained substantial levels of PSA (data not shown), but outgrowth was inhibited to the same extent as when endo- $\mathrm{N}$ was present throughout the culture resulting in removal of PSA from both the neurites and substrate.

For comparison with outgrowth on neuronal membranes, axon outgrowth was also monitored on an astrocyte monolayer substrate, which expresses neither PSA (Table 1; Noble et al., 1985) nor L1 (Grumet and Edelman, 1988; Rathjen and Schachner, 1984). As with the endo-N-treated neuronal substrate, the additional removal of PSA from the axons had no effect on outgrowth. However, the rate of outgrowth on the L1- and PSAnegative astrocytes was higher than on PSA-positive neuronal membranes.

Effect of adhesion-blocking antibodies on axon outgrowth. A 
A

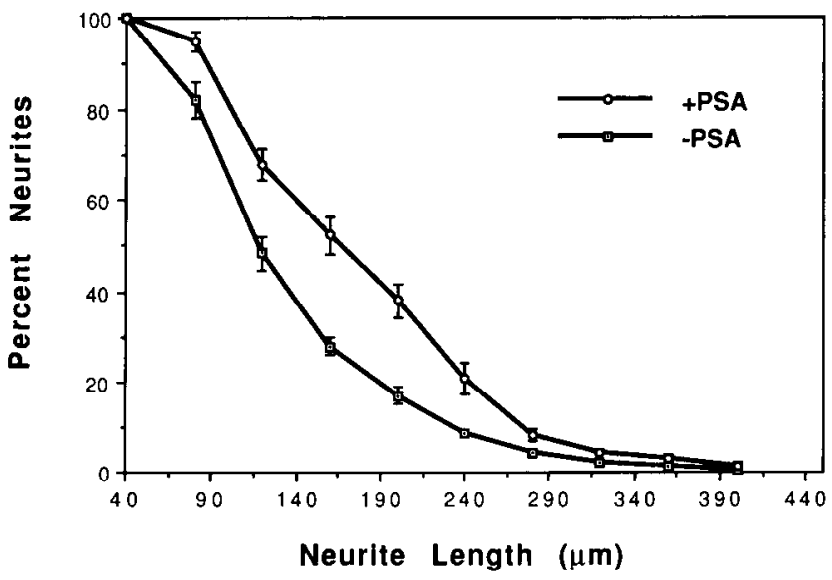

B

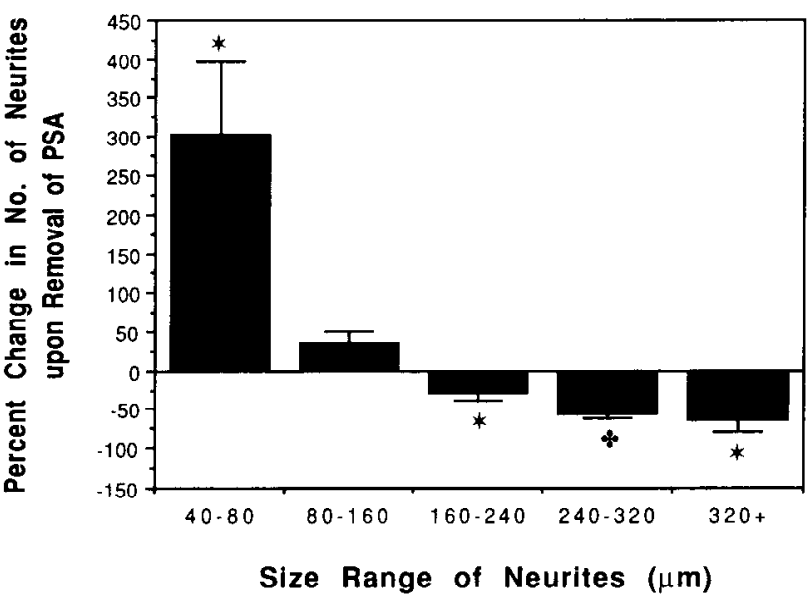

Figure 3. Removal of PSA causes a reduction in neurite outgrowth on a neuronal membrane substrate. E6 chick retinal neurons were cultured on the membrane vesicles for $24 \mathrm{hr}$, and the lengths of more than 600 neurites from four independent experiments were measured. Data pooled from four independent experiments are shown $(A)$ in which the percentage of neurites of, or great than, a specified length (vertical axis) is expressed as a function of neurite length (horizontal axis). To illustrate the preferential effect of PSA removal on the longest neurites, in the histogram $(B)$ the percentage change in number of neurites (vertical axis) within a specific length range is expressed as a function of the length of neurites (horizontal axis). Error bars, SEM. * and *, Significant differences of $p<0.025$ and $p<0.005$, respectively.

number of adhesion systems have been implicated in the outgrowth of axons on cellular substrates, including those involving NCAM, L1, N-cadherin, and integrins (see introductory remarks). In order to investigate which of these molecules might be influenced by PSA during neurite outgrowth, adhesion-inhibiting Fab fragments against each were added to the cultures in the presence and absence of endo-N. This analysis was carried out in terms of the proportion of axons capable of rapid growth (with lengths of greater than $160 \mu \mathrm{m}$; see Fig. $3 B$ ), as this was the parameter most affected by removal of PSA. As shown in Figure 4, with PSA intact (no endo-N), Fabs against each of these adhesion systems decreased the proportion of long axons, with anti- $\mathrm{N}$-cadherin and anti-L1 producing the largest effects (significantly different from controls, $p<0.01$ ). When PSA was

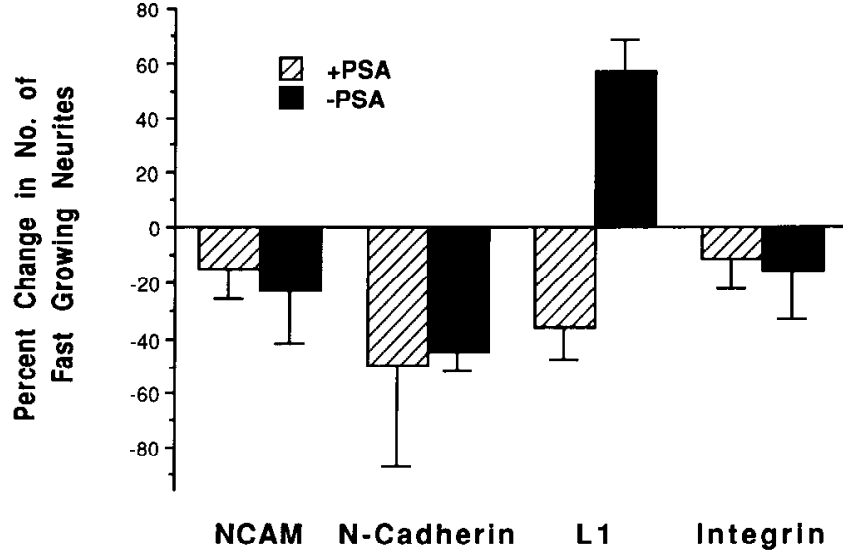

Figure 4. Effects of antibodies against NCAM, L1, N-cadherin, or $\beta_{1}$ integrin on neurite outgrowth in the presence or absence of PSA. In each case, the percentage change in number of fast-growing neurites $(>160 \mu \mathrm{m})$ is indicated. While the presence of antibodies to NCAM, $\mathrm{L} 1, N$-cadherin, and $\beta_{1}$-integrin all caused reduction of neurite outgrowth in the presence of PSA, and removal of PSA did not significantly alter these effects, the inhibitory effect of anti-Ll was actually reversed by removal of PSA. Error bars indicate SEM for over 200 ncurites scorcd in three independent experiments (two experiments with anti-N-cadherin).

removed by endo- $\mathrm{N}$ treatment, the influences of Fab against $\mathrm{N}$-cadherin, and integrin were not significantly altered $(p<$ $0.01)$. The same was true for anti-NCAM $(p<0.01)$, despite the fact that the PSA is attached to this molecule.

The only significant effect of PSA removal on Fab perturbation was in the case of anti-L1 ( $p<0.001$; Fig. 4). Unlike the other adhesion systems tested, antibodies that inhibit Ll function reversed the the effect of endo- $\mathrm{N}$ on neurite outgrowth, resulting in longer processes. This reversal of endo-N's effects on process outgrowth by anti-L1 Fab suggests that $\mathrm{L} 1$ function may be intimately involved in the influence of PSA on neurite outgrowth.

Enhancement of cell-cell adhesion by removal of PSA also reflects an increase in L1 function. The effect of PSA on axon outgrowth could reflect a dircct change in cell-cell adhesion, and/or an indirect influence on intracellular mechanisms that support growth cone motility. In order to assess whether the effects of PSA are an adhesion-related phenomenon, the same

Table 1. Effect of PSA on mean length of neurites

\begin{tabular}{|c|c|c|c|c|}
\hline \multirow[b]{2}{*}{ Substrate } & \multicolumn{2}{|c|}{ PSA on: } & \multirow[b]{2}{*}{$\begin{array}{l}\text { Mean } \\
\text { length }(\mu \mathrm{m})\end{array}$} & \multirow{2}{*}{$\begin{array}{l}\text { Average } \\
\text { rate of } \\
\text { growth }\end{array}$} \\
\hline & $\begin{array}{l}\text { Sub- } \\
\text { strate }\end{array}$ & $\begin{array}{l}\text { Neu- } \\
\text { rite }\end{array}$ & & \\
\hline \multirow[t]{3}{*}{ Tectal membrane } & + & + & $184 \pm 7^{*}$ & $7.7 \pm 0.3$ \\
\hline & - & - & $142 \pm 8^{*}$ & $5.9 \pm 0.3$ \\
\hline & - & + & $134 \pm 4$ & $5.6 \pm 0.2$ \\
\hline \multirow[t]{2}{*}{ Astrocyte monolayer } & - & + & $137 \pm 8$ & $8.6 \pm 0.5$ \\
\hline & - & - & $140 \pm 6$ & $8.8 \pm 0.4$ \\
\hline
\end{tabular}

On tectal membranes, the length of more than 600 E6 chick retinal neurites was measured after $24 \mathrm{hr}$ in culture. On the astrocyte substrate, the length of 200 neurites was measured after $16 \mathrm{hr}$ in culture. Values represent mean length $\pm S E M$. Since the rate of neurite outgrowth is approximately linear within the culture period (Smith et al., 1990), the average rate of neurite outgrowth was calculated and the values represent the average rate \pm SEM. Thus, in all cases retinal neurites grew faster on the astrocyte substrate than on tectal membranes. Significance of the difference in outgrowth was determined by $t$ test.

* Paired values were different significantly $(p<0.001)$. 


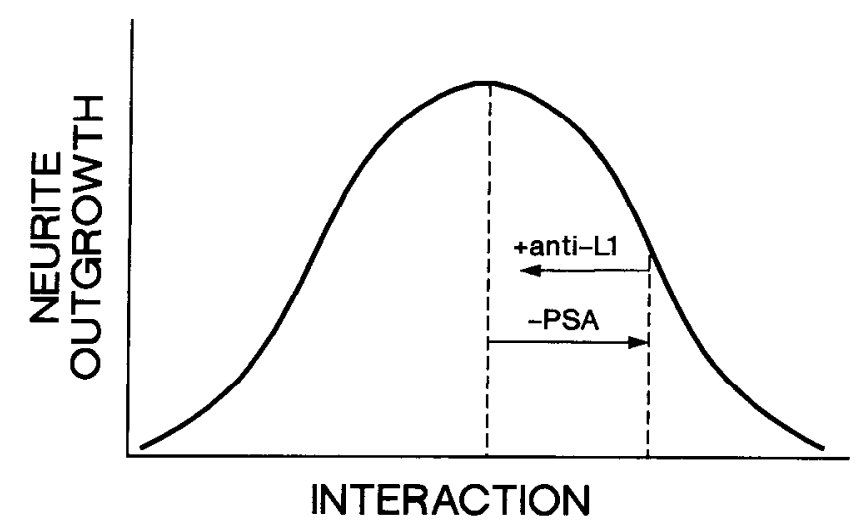

Figure 5. Proposed relationship between adhesion-related cell interaction and the extent of neurite outgrowth on a neuronal substrate. The ascending portion of the curve represents the ability of growth conesubstrate adhesion to promotc motility, whereas the descending portion reflects the proposal that increased interaction can decrease outgrowth. PSA is depicted as a regulator of interactions to optimal levels by attenuation of adhesion molecule function. In particular, this role of PSA appears to influence most strongly the action of the L1 adhesion molecule. Thus, the loss of PSA can be compensated by an inhibition of Ll by anti-Ll Fab.

perturbation studies were carried in a short-term aggregation assay using F1l neuroblastoma/neuronal cells (Table 2). As in the case of the retinal axons and membrane substrate, F11 cells express NCAM, L1, and N-cadherin, as well as PSA (Acheson et al., 1991). In the presence of PSA, inhibition of each of these three adhesion systems caused about the same amount of decrease in aggregation. That is, each appeared to contribute substantially to the adhesion. Upon removal of PSA by endo-N, the rate of aggregation increased but was much more dependent on $\mathrm{L} 1$ function. Thus, a dominance of $\mathrm{L} 1$ function after removal of PSA is observed in both the axon outgrowth and cell adhesion assays.

\section{Discussion}

Our findings indicate that the rate of axon outgrowth on a neuronal substrate is increased when PSA is present on both the axon and substrate. These effects are most pronounced for rapidly growing fibers, suggesting that PSA serves to optimize growth but is not an essential component in growth cone translocation. The decrease in outgrowth observed upon enzymatic removal of PSA appears to involve an increase in interactions mediated by the $L .1$ adhesion molecule. The observation that removal of PSA also causes a selective augmentation of $\mathrm{LI}$ function in a short-term cell aggregation assay suggests that the decrease in outgrowth includes an adhesion-related mechanism. While it is well established that adhesion to substrate is required for axon elongation, it has also been suggested that excessive adhesion would hinder translocation of the growth cone (Letourneau and Wessells, 1974). These positive and negative roles for adhesionrelated events are illustrated schematically in Figure 5, and provide a hypothetical basis for interpretation of our results.

PSA, which is a major constituent of axonal surfaces in embryos, has been proposed to serve as a negative regulator of cell-cell interactions (Rutishauser et al., 1988; Rutishauser, 1989). By controlling the degree of receptor-receptor interaction, PSA would be in a position to limit adhesion and thereby optimize conditions for axon growth (Fig. 5). This possibility is

Table 2. Effect of PSA, NCAM, L1, and calcium-dependent
adhesion on F11 cell aggregation
\begin{tabular}{lrlrr} 
PSA & Control & tanti-NCAM & +anti-Ll & \multicolumn{1}{l}{$-\mathrm{Ca}^{2+}$} \\
\hline+ & $37 \pm 2$ & $12 \pm 1(68 \%)$ & $22+1(40 \%)$ & $18 \pm 2(51 \%)$ \\
- & $49 \pm 2$ & $40 \pm 3(18 \%)$ & $9 \pm 2(81 \%)$ & $43 \pm 3(12 \%)$ \\
\hline
\end{tabular}

Extent of F11 cell aggregation is expressed as the percentage decrease in cell number after rotation at $70 \mathrm{rpm}$ for $30 \mathrm{~min}$ at $37^{\circ} \mathrm{C}$. Data are means $\pm S E M$ of nine values from three independent experiments. Values in parentheses represent the percentage decrease in aggregation.

supported by the present observation that the removal of PSA can inhibit neurite outgrowth. The fact that maximal outgrowth on tectal membranes was obtained only when PSA was present on both substrate and neurite parallels the observation that cellcell adhesion is most strongly inhibited when both membranes contain PSA (Hoffman et al., 1982; Hoffman and Edelman, 1983).

Several adhesion molecules have been found to influence process elongation on cellular substrates (Tomaselli et al., 1986, 1988; Chang et al., 1987; Landmesser et al., 1988; Smith et al., 1990). However, while PSA is physically associated with NCAM, the present Fab-perturbation studies appear to single out $\mathrm{Ll}$ as a central component in this decrease. That is, NCAM, N-cadherin, and integrins each continued to promote axon elongation after PSA removal, whereas $\mathrm{Ll}$ became a negative factor that could be neutralized by anti-L1. In this respect, it is notable that outgrowth on an astrocyte substrate, which does not contain $\mathrm{Ll}$, is both unaffected by PSA removal from the axons and even more rapid than on a PSA-positive neuronal substrate.

On this basis and in terms of the model illustrated in Figure 5, we propose that PSA removal causes an enhancement of L1mediated interactions to levels that impede growth cone migration. Addition of anti-L1 Fab then would reduce that interaction to more optimal levels. Consistent with the interpretation that L1's action involves adhesion, wc found that the removal of PSA causes a specific upregulation of L1-mediated cell-cell aggregation in a short-term assay.

Why is L1 so prominent, or conversely, why do antibodies against other adhesion molecules not also reverse the effects of endo-N? It is reasonable to suspect that the roles of different adhesion molecules on axons are not entirely interchangeable. For example, it may be that some interactions influence the behavior of filopodia and lamellapodia, while others tend to stabilize translocation of the entire growth cone. Enhanced interactions that support membrane movement might only augment growth cone motility (as observed with integrins, cadherin, NCAM) whereas excessive stabilization could hinder translocation (as observed with L1). Thus, the enhancing and inhibiting effects of adhesion on process outgrowth depicted in Figure 5 may well reflect the consequences of different adhesion systems acting in distinct spatial and/or functional rcgions of the growth cone (Letourneau and Shattuck, 1989). Such regional specialization is consistent with reflection interference studies that indicate that only small regions of the growth cone are in close contact with a laminin substrate, whereas almost the entire base of the growth cone is in close contact with an Ll substrate (J. Drazba and V. Lemmon, personal communication).

Previous studies from other laboratories on NCAM, PSA, and/or Ll have suggested indirect mechanisms for regulation 
of adhesion molcculc function. Augmentation of adhesion by a direct and specific interaction between NCAM and L1 has been proposed (Kadmon et al., 1990a,b). The proposed synergism appears to be inhibited rather than enhanced by agents that block glycosylation, and thus may be distinct from the present effects with PSA. A recent study has demonstrated that PSA removal from retinal axons can also inhibit their growth on a substrate of fibroblasts transfected with NCAM cDNA (Doherty et al., 1990a). In this system, it speculated that the removal of PSA could result in an instructive signal that reduces neurite outgrowth. It should be noted, however, that the transfected cells express neither L1 or PSA, which in our studies were essential elements. In any case, if an instructive mechanism operates in our system, it would appear to be masked by the effects of Ll or countered by some type of growth-promoting signal generated specifically by anti-Ll.

The fact that promotion of outgrowth on a ncuronal substratc only occurred when both the axon and substrate expressed PSA may have important biological implications. Many environments through which axons grow do not express PSA, including most glial cells and muscle cells as well as more mature neurons. In the absence of other factors, this asymmetry between axonaxon and axon-environment interactions would be expected to influence not only the rate of outgrowth, but also the formation and branching of axon bundles. For example, during innervation of muscle in the chick hindlimb, axons must choose whether to grow on other PSA-positive axons or on PSA-negative myotubes (Landmesser et al., 1988). In this system, developmental regulation of PSA expression has been shown to alter the balance of nerve-nerve and nerve-muscle interaction and thereby regulate specific patterns of axonal outgrowth during normal innervation. Moreover, this alteration appears to also involve augmentation of $\mathrm{L} 1$ function between axons (Landmesser et al., 1990). For the retinal axons studied here, the choices include other optic axons and PSA-negative radial glia (Silver and Sapiro, 1981; Silver and Rutishauser, 1984) and could contribute to a variety of stereotyped patterns in the optic nerve, fissure, chiasm, and tract. Therefore, it will be of interest to investigate whether different levels of PSA expression also exist within the optic nerve and if they can be linked to changes in the position and branching of axons along the visual pathway and during tectal innervation.

\section{References}

Acheson A, Sunshine JL, Rutishauser U (1991) NCAM polysialic acid can regulate both cell-cell and cell-substrate interaction. J Cell Biol 114:143-154.

Bixby JL (1989) Protein kinase $C$ is involved in laminin stimulation of neurite outgrowth. Neuron 3:287-297.

Bixby JL, Zhang R (1990) Purified N-cadherin is a potent substrate for the rapid induction of neurite outgrowth. J Cell Biol 110:12531260.

Boisseau S, Nedelec J, Poirier V, Rougon G, Simonneau M (1991) Analysis of high PSA N-CAM expression during mammalian spinal cord and peripheral nervous system development. Development 112 : $69-82$.

Bottenstein J, Sato GH (1979) Growth of a rat neuroblastoma cell line in serum-free supplemented medium. Proc Natl Acad Sci USA $76: 514-517$

Breen KC, Regan CM (1988) Differentiation-dependent sialylation of individual neural cell adhesion molecule polypeptides during postnatal development. J Neurochem 50:712-716.

Chang S, Rathjen FG, Raper J (1987) Extension of neurites on axons is impaired by antibodies against specific neural cell surface glycoproteins. J Cell Biol 104:355-362.
Dodd J, Morton SB, Karagogeos D, Yamamoto M, Jessell TM (1988) Spatial regulation of axonal glycoprotein expression on subsets of embryonic spinal neurons. Neuron 1:105-116.

Doherty P, Fruns M, Seaton P, Dickson G, Barton CH, Sears TA, Walsh FS (1990a) A threshold effect of the major isoforms of NCAM on neurite outgrowth. Nature 343:464-466.

Doherty P, Cohen J, Walsh FS (1990b) Neurite outgrowth in response to transfected NCAM changes during development and is modulated by polysialic acid. Neuron 5:209-219.

Finne J, Finne U, Deagostini-Bazin H, Goridis C (1983) Occurrence of a-2,8 linked polysialosyl units in a neural cell adhesion molecule. Biochem Biophys Res Commun 112:482-487

Frelinger AL III, Rutishauser U (1986) Topography of NCAM structural and functional determinants. II. Placement of monoclonal antibody cpitopes. J Ccll Biol 103:1729-1737.

Furley AJ, Morton SB, Manalo D, Karagogeos D, Dodd J, Jessell TM (1990) The axonal glycoprotein TAG-1 is an immunoglobulin superfamily member with neurite outgrowth-promoting activity. Cell 61:157-170.

Gozes I, Barnstable CJ (1982) Monoclonal antibodies that recognize discrete forms of tubulin. Proc Natl Acad Sci USA 79:2579-2583.

Greve JM, Gottlieb DI (1982) Monoclonal antibodies which alter the morphology of cultured chick myogenic cells. J Cell Biochem 18:221229.

Grumet M, Edelman GM (1988) Neuron-glia cell adhesion molecule interacts with neurons and astroglia via different binding mechanisms. J Cell Biol 106:487-503.

Hallenbeck PC, Vimr ER, Yu F, Hassler B, Troy FA (1987) Purification and properties of a bacteriophage-induccd cndo- $\mathrm{N}$-acetylncuraminidase specific for poly-a-2,8-sialosyl carbohydrate units. J Biol Chem 262:3553-3561.

Hatta K, Takeichi M (1986) Expression of N-cadherin molecules associated with early morphogenetic events in chick development. $\mathrm{Na}$ ture 320:447-449.

Hoffman S, Edelman GM (1983) Kinetics of homophilic binding by embryonic and adult forms of the neural cell adhesion molecule. Proc Natl Acad Sci USA 80:5762-5766.

Hoffman S, Sorkin BC, Brackenbury R, Mailhammer R, Rutishauser U, Cunningham BA, Edelman GM (1982) Chemical characterization of a neural cell adhesion molecule purified from embryonic brain membranes. J Biol Chem 257:7720-7729.

Kadmon G, Kowitz A, Altevogt P, Schachner M (1990a) The neural cell adhesion molecule N-CAM enhances $\mathrm{L} 1$-dependent cell-cell interactions. J Cell Biol 110:193-208.

Kadmon G, Kowitz A, Altevogt P, Schachner M (1990b) Functional cooperation between the neural adhesion molecules $\mathrm{L} 1$ and N-CAM is carbohydrate dependent. J Cell Biol 110:209-218.

Kapfhammer JP, Raper JA (1987) Collapse of growth cone structure on contact with specific neurites in culture. J Neurosci 7:201-212.

Lagenaur C, Lemmon V (1987) A L1-like molecule, the 8D9 antigen, is a potent substrate for neurite extension. Proc Natl Acad Sci USA 84:7753-7757.

Landmesser L, Dahm L, Schultz K, Rutishauser U (1988) Distinct roles of adhesion molecules during innervation of embryonic chick muscle. Dev Biol 130:645-670.

Landmesser L, Dahm L, Tang J, Rutishauser U (1990) Polysialic acid as a regulator of intramuscular nerve branching during embryonic development. Neuron 4:655-667.

Lemmon V, Farr K, Lagenaur C (1989) Ll mediated axon outgrowth occurs via a homophilic binding mechanism. Neuron 2:1597-1603.

Lemmon V, Burden SM, Payne HR, Elmslie GJ, Hlavin ML (1992) Neurite growth on different substrates: permissive versus instructive influences and the role of adhesive strength. J Neurosci 12:818-826.

Letourneau PC (1975a) Possible roles for cell-to-substratum adhesion in neuronal morphogenesis. Dev Biol 44:77-91.

Letourneau PC (1975b) Cell-to-substratum adhesion and guidance of axonal elongation. Dev Biol 44:92-101.

Letourneau PC, Shattuck TA (1989) Distribution and possible interactions of actin-associated proteins and cell adhesion molecules of nerve growth cones. Development 105:505-519.

Letourneau PC, Wessells NK (1974) Migratory cell locomotion versus nerve axon elongation: differences based on the effects of lanthanum ion. J Cell Biol 61:56-69.

Miragall F, Kadmon G, Faissner A, Antonicek H, Schachner M (1990) Retention of $\mathrm{J} 1 /$ tenascin and the polysialylated form of the neural 
cell adhesion molecule (N-CAM) in the adult olfactory bulb. J Neurocytol 19:899-914.

Neugebauer KM, Reichardt LF (1991) Cell-surface regulation of b1integrin activity on developing retinal neurons. Nature 350:68-71.

Noble M, Fok-Seang J, Cohen J (1984) Glia are a unique substrate for the in vitro growth of central nervous system neurons. J Neurosci 4:1892-1903.

Noble M, Albrechtsen M, Moller C, Lyles J, Bock E, Goridis C, Watanabe M, Rutishauser U (1985) Glial cells express N-CAM/D2CAM-like polypeptides in vitro. Nature 316:725-728.

Platika D, Boulous MH, Baizer L, Fishman MC (1985) Neuronal traits of clonal cell lines derived by fusion of dorsal root ganglia neurons with neuroblastoma cells. Proc Natl Acad Sci USA 82:3499-3503.

Raper JA, Grunewald EB (1990) Temporal retinal growth cones collapse on contact with nasal retinal axons. Exp Neurol 109:70-74.

Rathjen FG, Schachner M (1984) Immunocytological and biochemical characterization of a new neuronal cell surface component (L1 antigen) which is involved in cell adhesion. EMBO J 3:1-10.

Rathjen FG, Wolff JM, Frank R, Bonhoeffer F, Rutishauser U (1987) Membrane glycoproteins involved in neurite fasciculation. J Cell Biol 104:343-353.

Ruegg MA, Stoeckli ET, Lanz RB, Streit P, Sonderegger P (1989) A homologue of the axonally secreted protein axonin-1 is an integral membrane protein of nerve fiber tracts involved in neurite fasciculation. J Cell Biol 109:2363-2378.

Rutishauser U (1989) Polysialic acid as a regulator of cell interactions. In: Neurobiology of glycoconjugates (Margolis RU, Margolis RK, ed), pp 367-379. New York: Plenum.

Rutishauser U, Watanabe M, Silver J, Troy FA, Vimr ER (1985) Specific alteration of NCAM-mediated cell adhesion by an endoneuraminidase. J Cell Biol 101:1842-1849.

Rutishauser U, Acheson A, Hall AK, Mann DM, Sunshine J (1988) The neural cell adhesion molecule (NCAM) as a regulator of cell-cell interactions. Science 240:53-57.
Schlosshaucr B, Schwarz U, Rutishauser U (1984) Topological distribution of different forms of neural cell adhesion molecule in the developing chick visual system. Nature 310:141-143.

Schuch U, Lohse M, Schachner M (1989) Neural cell adhesion molecules influence second messenger systems. Neuron 3:13-20.

Silver J, Rutishauser U (1984) Guidance of optic axons in vivo by a preformed adhesive pathway on neuroepithelial endfeet. Dev Biol 106:485-499.

Silver J, Sapiro J (1981) Axonal guidance during development of the optic nerve: the role of pigmented epithelia and other extrinsic factors. J Comp Neurol 202:521-538.

Smith GM, Rutishauser U, Silver J, Miller RH (1990) Maturation of astrocytes in vitro alters the extent and molecular basis of neurite outgrowth. Dev Biol 138:377-390.

Stoeckli ET, Kuhn TB, Duc CO, Ruegg MA, Sonderegger P (1991) The axonally secreted protein axonin-1 is a potent substratum for neurite growth. J Cell Biol 112:449-455.

Theodosis DT, Rougon G, Poulain DA (1991) Retention of embryonic features by an adult neuronal system capable of plasticity: polysialylated neural cell adhesion molecule in the hypothalamo-neurohypophysial system. Proc Natl Acad Sci USA 88:5494-5498.

Tomaselli KJ, Reichardt L, Bixby JL (1986) Distinct molecular interactions mediate neuronal process outgrowth on non-neuronal cell surfaces and extracellular matrices. J Cell Biol 103:2659-2672.

Tomaselli KJ, Neugebauer KM, Bixby JL, Lilien J, Reichardt LF (1988) $\mathrm{N}$-cadherin and integrins: two receptor systems that mediate neuronal process outgrowth on astrocyte surfaces. Neuron 1:33-43.

Vimr ER, McCoy RD, Vollger HF, Wilkison NC, Troy FA (1984) Use of prokaryotic-derived probes to identify poly(sialic acid) in neonatal neuronal membranes. Proc Natl Acad Sci USA 81:1971-1975.

Walter J, Kern-Veits B, Huf J, Stolze B, Bonhoeffer F (1987) Recognition of position-specific properties of tectal cell membranes by retinal axons in vitro. Development 101:685-696. 